\title{
Consideraciones ambientales sobre el proceso penal
}

\author{
PIERRE FOY VALENCIA*
}

\begin{abstract}
SUMARIO: INTRODUCCIÓN.- I. CODIFICACIÓN O TIPIFICACIÓN PENAL AMBIENTAL COMPARADA.- II. LA JUSTICIA AMBIENTAL COMO MARCO GENERAL.- III.ELDERECHO PENAL AMBIENTAL PERUANO.-IV.EXPERIENCIAS COMPARADAS EN ASUNTOS PROCESALES PENALES AMBIENTALES.V. PREOCUPACIONES EN MATERIA PROCESAL DE LA JUSTICIA PENAL AMBIENTAL.
\end{abstract}

\section{INTRODUCCIÓN}

Resulta interesante advertir en la experiencia comparada latinoamericana «la presencia de órganos especializados dentro de vías procesales penales ordinarias, tales como fiscalías, cuerpos policiales e incluso juzgados especializados», así como comprobar que en esta región se viene dando el mayor auge del procesal penal ambiental — sin obviar su desarrollo sustantivo al amparo de su base constitucional ${ }^{1}-$, con lo que se ha revertido la tradicional imagen de copiar los institutos y normas de las legislaciones europeas. Es más, destaca el caso particular de México, donde se viene discutiendo un proyecto de ley para establecer una jurisdicción especializada en el penal ambiental².

Una mirada en términos de sistema o subsistema respecto del derrotero normativo penal ambiental de nuestro país nos deja una cierta desazón, ante lo incompleto, en términos jurídico-institucionales, de la cuestión. Si bien es cierto que se ingresó a una reforma sustantiva en materia

* Es profesor asociado de la Pontificia Universidad Católica del Perú en Derecho Ambiental, magíster en Derecho Ambiental por la Universidad del País Vasco, miembro y fundador del Instituto de Estudios Ambientales (IDEA-PUCP), docente en la Facultad de Derecho de la Universidad de Lima (Derecho Ambiental), la UNMSM (Ecología Política, Derecho del Ordenamiento del Territorio) y la UNALM (Derecho y Legislación Ambiental y de los Recursos Naturales). También es conductor del Estudio Foy Valencia Abogados - Derecho Ambiental y de los Recursos Naturales, gerente del Estudio Foy \& Valdez, miembro del Consorcio Derecho Ambiental Consultor e investigador con diversas publicaciones en su especialidad. E-mail: pfoy@ pucp.edu.p.

1 A continuación se presentan algunos textos constitucionales comparados sobre justicia penal ambiental: Brasil (1988). Artículo 255 - 3: Refiere que los infractores, sean personas jurídicas o naturales, que realicen conductas y actividades consideradas lesivas al medio ambiente están sujetos a sanciones penales y administrativas, independientemente de la obligación de reparar los daños causados. Colombia (1991). Artículo 277: «El procurador General de la Nación [...] tendrá las siguientes funciones: 4. Defender los intereses colectivos, en especial el ambiente». España (1978). Artículo 45- 3. «Para quienes violen lo dispuesto en el apartado anterior, en los términos que la ley fije se establecerán sanciones penales, o, en su caso, administrativas, así como la obligación de reparar el daño causado». Paraguay (1992). Artículo 8. «El delito ecológico será definido y sancionado por la ley. Todo daño al ambiente importará la obligación de recomponer e indemnizar».

2 ARCe Guillén, Mario y Mariana HeRrera UGaRTE. "Costa Rica: rumbo a un proceso penal ambiental». Tesis para optar por el grado de Licenciatura en Derecho, 2009, p. 301-302. En לttp:// iij.derecho.ucr.ac.cr/archivos/documentacion/tesis/2009/tesis\%20proceso\%20penal\%20ambiental. pdifs. 
penal ambiental a fines del año $2008^{3}$, esto no ha sido correspondido en lo que concierne al venido con un desarrollo orgánico institucional de las agencias penales pertinentes. Esto se puede observar en la implementación, aún parcial e insuficiente, de fiscalías penales ambientales ${ }^{4}$; la inexistencia de jueces penales ambientales; una agencia policial ecológica sin una reinstitucionalización seria que la convierta en una policía nacional ambiental rezagada, y la carencia de peritos penales ambientales.

\section{CODIFICACIÓN O TIPIFICACIÓN PENAL AMBIENTAL COMPARADA}

La normativa penal ambiental comparada nos ofrece diferentes tratamientos en cuanto a política legislativa. En buena cuenta, el desarrollo de la legislación secundaria que criminaliza conductas lesivas al medio ambiente se puede encuadrar en cuatro vías o modelos que se expresan mediante $^{5}$ :

- Leyes sectoriales protectoras de ciertos recursos naturales. En el Perú era el caso de la antigua Ley Forestal y de Fauna Silvestre (1975), el Código Sanitario (1969, derogado en 1997 por la Ley General de Salud) y la Ley sobre Camélidos y Delfines.

- Leyes generales ambientales. Decreto legislativo 613 CMARN (capítulo «De los delitos y las penas», vigente hasta noviembre de 1991, derogado por el decreto legislativo 757).

- Códigos penales como el peruano (decreto legislativo 635 de 1991), el colombiano ${ }^{6}$, el alemán ${ }^{7}$ y el español ${ }^{8}$. En relación con

3 La ley 29263, publicada en el diario El Peruano, modificó el Código Penal y la Ley General del Ambiente de tal forma que los delitos contra el medio natural serán sancionados con pena privativa de libertad entre dos y diez años. Véase al respecto PeÑA CABRERA FreYRE, Alonso R. Los delitos contra el medio ambiente. Lima: Rodhas, 2010, p. 563.

4 Véase la exposición de Felipe Villavicencio titulada «Retos del Derecho penal para la protección del medio ambiente», en el curso de Inmersión en Materia Ambiental del Ministerio Público para las Fiscalías Especializadas en Materia Ambiental. Lima, julio de 2008.

5 Véase El acceso a la justicia ambiental en América Latina: Derecho ambiental y desarrollo sostenible, del doctor Raúl Brañes Bruñesen, en especial el capítulo «La justicia penal». En Simposio Judicial sobre Derecho Ambiental y Desarrollo Sostenible. El acceso a la justicia ambiental en América Latina. Ciudad de México, 26 al 28 de enero de 2000. Capítulo IV: "Justicia Penal». México, ALDA.

6 Código Penal Colombiano (1980): Explotación y tráfico de recursos naturales. Agravante por especie en vías de extinción (artículo 242). Ocupación ilícita de reserva forestal o parque nacional (artículo 243). Explotación ilícita de yacimiento minero (artículo 244). Transmisión y propagación de daño a recursos vivos (artículo 245). Destrucción, inutilización o desaparición de recursos naturales (artículo 246). Contaminación ilícita del ambiente (artículo 247).

7 Código Penal Alemán (1980). Título 28. Parágrafos: (324) Contaminación del agua; (325) Contaminación del aire y ruido; (326) Eliminación de residuos peligrosos para el ambiente; (327) Funcionamiento no autorizado de instalaciones; (328) Manipulación no autorizada de combustible nuclear; (329) Puesta en peligro de zonas necesitadas de protección; (330) Grave puesta en peligro del ambiente; (330a) Grave puesta en peligro a través de la emisión de veneno; (330b) Arrepentimiento activo; (330c) Comiso; (330d) Definiciones.

8 Código Penal Español (1995). Título XVI. De los delitos relativos a la ordenación del territorio y la protección del patrimonio histórico y del medio ambiente. Capítulo I. De los delitos sobre la ordenación del territorio. Artículos 319 al 320. Capítulo II. De los delitos contra el patrimonio histórico. Artículos 321 al 324. Capítulo III. De los delitos contra los recursos naturales y el medio ambiente. Artículo 325: Perjuicio al equilibrio de los sistemas naturales. Artículo 325 (in fine): Agravamiento por la salud de las personas. Artículo 326: Circunstancias cualificantes. Artículo 327: Medidas judiciales del Artículo 129. Artículo 328: Tipo residual (depósitos o vertederos). Artículo 329: Prevaricación específica. 
la criminalización penal ambiental alemana, es aleccionadora la pauta del jurista chileno Jean Pierre Matus Acuña cuando refiere:

Por su parte, la legislación alemana reunió (18 Ley de Reforma del Derecho Penal de 1980 y Segunda Ley para el Combate de la Criminalidad Ambiental de 199431 Ley de Reforma del Derecho Penal) en el actual Capítulo 29 de su Código penal, $\$ \$ 324$ ss, bajo el epígrafe «Delitos contra el medio ambiente», la mayor parte de los hechos de contaminación punibles que recaen sobre los «medios del ambiente», estableciendo tipos penales diferentes para cada uno de ellos (agua, aire, suelo), junto con previsiones específicas para la protección de la flora y fauna, figuras penales antes dispersas en leyes especiales, siguiendo al decir de Tiedemann «la nueva política criminal alemana de ubicar todos los delitos importantes en el Código Penal común», pues «son los delitos incluidos en el Código Penal los que interesan no sólo (y en cuanto tales) al público sino especialmente a los juristas, comenzando por los estudiantes y terminando por los jueces y por la doctrina penal», como una forma de hacer patente «la idea de que estamos ante una verdadera delincuencia [que] merece ser tomada seriamente en cuenta» ${ }^{9}$.

\section{- Leyes penales ambientales especiales:}

1. Brasil. Ley 9.605 (1998) sobre crímenes ambientales.

2. Venezuela. Ley Penal del Ambiente (1992) ${ }^{10}$.

Artículo 330: Cualificación por afectación de espacio natural protegido. Artículo 331: Pena inferior en grado ante imprudencia grave. Capítulo IV. De los delitos relativos a la protección de la flora y fauna. Artículos 332 al 337. Capítulo V. Disposiciones comunes. Artículo 338: Supercualificación por afectación de espacio natural protegido. Artículo 339: Consecuencias jurídicas del hecho: «Restauración del equilibrio ecológico perturbado». Artículo 340: Consecuencias jurídicas del hecho: Atenuante calificada de reparación del daño. Revísese el estudio de Jesús-María Silva Sánchez titulado Delitos contra el medio ambiente. Valencia: Tirant lo Blanch, 1999.

9 Véase MATUS AcuÑA, Jean Pierre. «Análisis dogmático del Derecho penal ambiental chileno, a la luz del Derecho comparado y las obligaciones contraídas por Chile en el ámbito del Derecho internacional. Conclusiones y propuesta legislativa fundada para una nueva protección penal del medio ambiente en Chile». En http://www.scielo.cl/scielo.php?pid=S0718-00122003000200002\&script=sci_arttex\$.

10 Ley Penal del Ambiente de Venezuela (1992): Título I: Disposiciones generales. 1) Objeto. 2) Extraterritorialidad. 3) Requisitos de las sanciones a personas jurídicas. 4) Responsabilidad del representante. 5) Sanciones a personas naturales. 6) Sanciones a personas naturales. 7) Definición de salario mínimo. 8) Leyes penales en blanco. 9) Penalidades del delito culposo. Aumento de penalidad. 10) Agravante. 12) Aumento de penalidad. 13) Aumento de penalidad. 14) Aumento de penalidad. 15) Atenuante. 16) Obligación de orden público. 17) Prelación. 18) Destino de las recaudaciones. 19) Prescripción de acciones. 20) Acciones derivadas del delito. 21) Obligación del Ministerio Público. 22) Competencia. 23) Emplazamiento de personas jurídicas. 24) Medidas judiciales precautelativas. 25) Experticia de los daños. 26) Contenido de la sentencia. 27) Sentencia conminatoria. Título II: De los delitos contra el ambiente. Capítulo I. De la degradación, envenenamiento, contaminación y demás acciones o actividades capaces de causar daños a las aguas. 18) Vertido ilícito. 29) Alteración térmica. 30) Cambio de flujos y sedimentación. 31) Extracción ilícita de materiales. 32) Contaminación de aguas subterráneas. 33) Daños a las defensas de aguas. 34) Permisos o autorizaciones ilícitas. Capítulo II. Del deterioro, envenenamiento, contaminación y demás acciones o actividades capaces de causar daño al medio lacustre, marino y costero. 35) Descarga de contaminantes. 36) Construcción de obras contaminantes. 37) Degradación de las playas. 38) Contaminación por fugas o descargas. 39) Omisión de aviso. 40) Vertido de hidrocarburos. 41) Pesca ilícita. Capítulo III. De la degradación, alteración, deterioro, contaminación y demás acciones capaces de causar daño a los suelos, la topografía y el paisaje. 42) Actividades y objetos degradantes. 43) Degradación de suelos, topografía y paisaje. Capítulo IV. Del envenenamiento, contaminación y demás acciones capaces de alterar la atmósfera o el aire. 44) Emisión de gases. 45) Emisiones radioactivas. 46) Contaminación por unidades de transporte. 47) Degradación de la capa de ozono. Capítulo V. De la destrucción, contaminación y demás acciones capaces de causar daños a la flora, fauna, sus hábitats

CONSIDERACIONES AMBIENTALES SOBRE EL PROCESO PENAL 
3. Paraguay. Ley que sanciona delitos contra el medio ambiente. Ley 716 (1996).

4. Nicaragua. Ley 559, Ley Especial de Delitos contra el Medio Ambiente y los Recursos Naturales (2005) ${ }^{11}$.

\section{LA JUSTICIA AMBIENTAL COMO MARCO GENERAL La acepción de «justicia ambiental» que se ha venido planteando duran- te los últimos tiempos en la región ${ }^{12}$, en realidad proviene de la experien- cia norteamericana de los años ochenta, cuando un estudio demostró que tres de cada cuatro depósitos de desechos peligrosos se localizaban en comunidades afroamericanas, lo que hizo saltar a la palestra la discu- sión sobre la desigualdad (discriminación) respecto del riesgo ambien- tal $^{13}$. En nuestro país, se quiso consagrar esta denominación — aunque}

o a las áreas bajo régimen de administración especial. 48) Incendio de plantaciones. 49) Incendio de dehesa. 50) Incendio de vegetación natural. 51) Negativa de colaboración. 53) Destrucción de vegetación en las vertientes. 54) Difusión de gérmenes. 55) Difusión de enfermedades. 56) Obligación del Ministerio del Ramo. 57) Propagación ilícita de especies. 58) Actividades en áreas especiales o ecosistemas naturales. 59) Caza y destrucción en áreas especiales o ecosistemas naturales. 60) Daño a monumentos y yacimientos. Capítulo VI. De las omisiones en el estudio y evaluación del impacto ambiental. 61) Omisión de requisitos sobre impacto ambiental. Capítulo VII. De los desechos tóxicos o peligrosos. 62) Gestión de desechos tóxicos. 63) Introducir desechos tóxicos. Título III. Disposiciones finales y transitorias. Capítulo I. Disposiciones finales. 64) Supletoriedad. 65) Derogatoria. Capítulo II. Disposiciones transitorias. 66) Exención de penas para campesinos. 67) Régimen de excepción indígena 68) Disposiciones complementarias de la Ley. 69) Vacatio legis.

11 Ley Especial de Delitos contra el Medio Ambiente y los Recursos Naturales 559, 21 de noviembre de 2005. Capítulo 1. Disposiciones generales. Artículo 1. Objeto. Artículo 2. Competencia. Artículo 3. Definiciones. Artículo 4. Normas Técnicas. Artículo 5. Medidas cautelares. Capítulo II. Delitos contra el ambiente. Artículo 6. Contaminación del suelo. Artículo 7. Contaminación de aguas. Artículo 8. Contaminación atmosférica. Artículo 9. Contaminación por ruido. Artículo 10. Transporte de materiales y desechos tóxicos, peligrosos o contaminantes. Artículo 11. Almacenamiento, manipulación o derrame de sustancias tóxicas, peligrosas o contaminantes. Artículo 12. Desechos degradables o no biodegradables. Artículo 13. Aumento de las penas. Artículo 14. Penas para empleados o funcionarios públicos. Artículo 15. Violación a lo dispuesto en el Estudio de Impacto Ambiental (EIA). Artículo 16. Información falsa al EIA. Artículo 17. Funcionario que permita información falsa al EIA. Capítulo III. Delitos contra los recursos naturales. Artículo 18. Aprovechamiento ilegal de recursos naturales. Artículo 19. Desvío de corrientes de aguas. Artículo 20. Impedir aprovechamiento de las aguas. Artículo 21. Pesca en época de veda. Artículo 22. Trasiego de pesca o descartes en alta mar. Artículo 23. Pesca sin dispositivos de conservación. Artículo 24. Pesca con explosivos. Artículo 25. Pesca con bandera no autorizada. Artículo 26. Captura de especies de la biodiversidad. Artículo 27. Caza de animales en peligro de extinción. Artículo 28. Comercialización de fauna y flora. Artículo 29. Incendios forestales. Artículo 30. Tala rasa y veda forestal. Artículo 31. Talas en vertientes y pendientes. Artículo 32. Corte, transporte y comercialización ilegal de madera. Artículo 33. Corte o poda de árboles en casco urbano. Artículo 34. Incumplir con el Estudio de Impacto Ambiental (EIA). Artículo 35. Comercio ilegal de minerales. Capítulo IV. Otros delitos. Artículo 36. Lotificación, urbanización y construcción. Artículo 37. Daños físicos o maltrato a animales. Artículo 38. Incumplimiento de pago de canon o multas. Artículo 39. Introducción de especies invasoras, agentes biológicos o bioquímicos. Artículo 40. Alteración del entorno o paisaje natural. Artículo 41. Escala de intensidad de sonidos. Capítulo V. De la responsabilidad civil. Artículo 42. Cuantía de daños. Artículo 43. Reparación del daño. Artículo 44. Responsabilidad solidaria. Artículo 45. Indemnización. Artículo 46. Sanciones penales y administrativas. Artículo 47. Garantía financiera. Capítulo VI. De las multas. Artículo 48. Sentencia motivada. Artículo 49. Pago de multas. Artículo 50. Destino de las multas. Capítulo VII. Disposiciones comunes. Artículo 51. Decomiso. Artículo 52. Suspensión de la pena de prisión. Artículo 53. Reparación voluntaria. Artículo 54. Suspensión de licencias o permisos. Artículo 55. Atenuantes. Artículo 56. Dictámenes técnicos. Artículo 57. Perímetro para corte de árboles. Capítulo VIII. Disposiciones finales Artículo 58. Incorporación al Código Penal. Artículo 59. Previa difusión. Artículo 60. Vigencia.

12 BRAÑES, Raúl. El acceso a la justicia ambiental en América Latina... Ob. cit.

13 El primer estudio de «racismo ambiental» (1987) encontró que la composición racial del vecindario era el mejor predictor de dónde se ubicaría un depósito de sustancias tóxicas en Estados Unidos, más allá de otras variables medidas como ingreso, valor de la propiedad y proximidad a los mercados). GoldmAN, Benjamin. «What is the future of environmental justice?» En Antipode 28, 2, 1996, pp. 122141. Tomado de http://www.programabecas.org/numero/11/11.12.htm. Véase también BRYANT, 
no bajo tales consideraciones críticas- en un título sobre justicia ambiental en la discusión de la reforma del derogado Código del Medio Ambiente y los Recursos Naturales, que al final quedó bajo la acepción convencional de «responsabilidad por daño ambiental» en el Título IV de la Ley General del Ambiente (ley 28611) y una mención en el artículo de su título preliminar. En resumen, hoy día tanto en el escenario internacional como en el Derecho comparado y nacional se legitima el concepto de «acceso a la justicia ambiental». Los aspectos conceptuales y básicos de este tema los hemos abordado en el estudio anterior ${ }^{14}$.

\section{EL DERECHO PENAL AMBIENTAL PERUANO ${ }^{15}$}

Formalmente, no tiene más de veinte años en el país ${ }^{16}$. Las conductas inicialmente criminalizadas por el CMARN, y luego sometidas a un paralelismo normativo con el Código Penal de abril de 1991 finalmente son expresamente derogadas en noviembre de ese mismo año mediante el decreto legislativo 757. Así, hoy en día el Código Penal es el dispositivo criminalizador ambiental básico de nuestro sistema legal, incluyendo sus modificatorias, ampliatorias y leyes conexas. Desde el punto de vista procesal, la ley 26631 de 1996 estableció que el dictamen de la autoridad sectorial o administrativa constituía un requisito de procedibilidad para las acciones penales ambientales. Hoy, dicha norma, derogada por La Ley General del Ambiente (ley 28611) y sin embargo revivida simultáneamente cuando fue incorporada textualmente en el artículo 149 de dicho dispositivo, ha tomado otro tenor gracias a la mencionada ley que reforma los delitos ambientales (ley 29263). El desarrollo prolífico de la normativa administrativa permite progresivamente llenar los contenidos criminalizadores de las respectivas normas penales en blanco, ya sea a partir de los denominados límites máximos permisibles (LMP) o de los estándares de calidad ambiental (ECA), para lo cual se cuenta un creciente aparato administrativo generador de tales normas ${ }^{17}$ —destacamos en este contexto orgánico institucional la creación del Ministerio del Ambiente-. De la misma forma, la Ley de Protección a los Animales Domésticos y Animales Silvestres Mantenidos en Cautiverio, ley 27265 (2000), ha incorporado el artículo 450-A como falta por crueldad

Bunyan (editor). Envionmental justice. Issues, policies, and solutions. Washington DC: Island Press, 1995.

14 Véase For, Pierre. "Consideraciones sobre la justicia ambiental en el sistema jurídico peruano». En Ensayos jurídicos contemporáneos. Nuevo testimonio de una huella académica. Lima: ARA, 2008, p. 121-149.

15 El principal texto nacional en materia penal ambiental ha sido el de Carlos Caro, Derecho penal del ambiente. Lima: Gráfica Horizontes, 1999. Sobre criminalidad ambiental en el país, aún no se ha elaborado un estudio sistemático.

16 Elaboramos un primer trabajo sobre la materia en 1992 en la revista de Derecho de la PUCP, $N^{\circ} 46$ : «Aproximación al estudio de la criminalidad y el Derecho penal ambiental peruano». Posteriormente, de manera complementaria, publicamos "Consideraciones sobre criminalidad ambiental y empresa", en la revista Criminología del Instituto de Criminología y Prevención del Delito. Lima, 1997, USMP, pp. 43-53.

17 Véase Revista de Derecho Administrativo, $\mathrm{N}^{\circ}$ 6, 2008, número especial sobre Derecho ambiental, Lima. 
contra los animales. Como ya se mencionó, recién se está implementando el nuevo Catálogo Penal Ambiental y es necesario entender la forma en la que el nuevo Código Procesal Penal va contribuir con el propósito político criminal ambiental.

\section{EXPERIENCIAS COMPARADAS EN ASUNTOS PROCESALES PENALES AMBIENTALES}

Veamos una breve referencia en torno a los elementos meramente procesales penales ambientales presentes en algunos países de la región sintetizando el trabajo de Arce y Herrera ${ }^{18}$ :

\begin{tabular}{|c|c|}
\hline & $\begin{array}{l}\text { Cuenta con una Unidad Fiscal de Investigación en Materia Ambiental } \\
\text { (UFiMA), la cual dispone la concreción de un acuerdo entre la Se- } \\
\text { cretaría de Ambiente y Desarrollo Sustentable y el Ministerio Público } \\
\text { Fiscal. Dicha unidad actúa a nivel nacional con fiscales ubicados en } \\
\text { diferentes regiones, desempeñando las siguientes funciones: } \\
\text { - colaborar con jueces y fiscales que llevan investigaciones vin- } \\
\quad \text { culadas a delitos contra el medio ambiente y la salud pública; } \\
\text { - iniciar investigaciones para combatir los delitos ambientales; } \\
\text { - recibir denuncias por casos de afectación ambiental; } \\
\text { - renovar la doctrina y jurisprudencia; y } \\
\text { - capacitar a los peritos en el tema ambiental. }\end{array}$ \\
\hline & $\begin{array}{l}\text { Cuando entra en vigencia la Ley del Nuevo Procedimiento Sancio- } \\
\text { natorio Ambiental, el Ministerio Público ejerce tutela en materia } \\
\text { ambiental vía el Procurador General de la Nación, quien delega tal } \\
\text { función al Procurador Delegado para Asuntos Ambientales y Agra- } \\
\text { rios (con treinta procuradores judiciales ambientales y agrarios bajo } \\
\text { su mando). } \\
\text { Dos de los procuradores ambientales y agrarios designados tienen com- } \\
\text { petencia en todo el territorio nacional. } \\
\text { Las funciones de los procuradores son velar por el estricto cumplimien- } \\
\text { to de lo dispuesto en la Constitución Política: leyes, decretos, actos } \\
\text { administrativos y demás actuaciones relacionadas con la protección } \\
\text { del medio ambiente y utilización de los recursos naturales. Las autori- } \\
\text { dades jurisdiccionales que conducen o toman conocimiento de proce- } \\
\text { sos sancionatorios ambientales, deberán notificar personalmente a los } \\
\text { procuradores judiciales ambientales y agrarios. }\end{array}$ \\
\hline
\end{tabular}


La acción penal en materia ambiental es conducida por fiscalías ambientales especializadas, creadas en 2008.

Tienen competencia para prevenir e investigar delitos ambientales y operan en los distritos judiciales de Tumbes, Piura Lambayeque, Loreto, Cajamarca, Amazonas y San Martín, Ucayali, Junín y Huánuco, Arequipa, Tacna y Moquegua, Cusco y Madre de Dios, Puno, Ayacucho, Huancavelica, Apurímac y Lima.

Existe una Fiscalía Provincial de Prevención de Delitos especializada en Delitos contra los Recursos Naturales, el Ambiente y Tala Ilegal, que realiza una función preventiva. Se limita a recomendar y exhortar a quien corresponda y a la realización de acciones que contribuyan a la prevención del delito denunciado.

Es el país con el mayor avance en establecer una jurisdicción penal ambiental. Hacia 2009, existía una iniciativa legislativa para el establecimiento de una jurisdicción penal ambiental especializada y separada de la jurisdicción penal ordinaria. Se logró organizar un Primer Encuentro Internacional sobre Jurisdicción Ambiental (Puerto Vallarta, estado de Jalisco).

En cuanto a los órganos existentes encargados de velar por el ambiente en el interior de la República Federal Mexicana, se encuentra la Fiscalía Especializada para la Atención de Delitos Ambientales (FEPADA), que constituye una unidad especializada de delitos contra el ambiente y previstos en leyes especiales.

Esta fiscalía conoce de los delitos que afectan al ambiente, en específico a los contemplados por las leyes ambientales y en el título XXV del Código Penal.

Se faculta a quien conozca de la comisión de cualquier delito ambiental —ya sea la Secretaría del Medio Ambiente y Recursos Naturales, la Procuraduría Federal de Protección al Ambiente o cualquier ciudadano- para que pueda llevar a cabo la denuncia ante el Ministerio Público Federal.

La Procuraduría Federal de Protección al Ambiente es un órgano desligado de la Secretaría de Medio Ambiente, Recursos Naturales y Pesca, y se encarga de recibir, investigar, atender y canalizar las denuncias recibidas en materia ambiental, así como de verificar el cumplimiento de la legislación ambiental; ello la faculta para iniciar procedimientos administrativos en caso de incumplimiento de las disposiciones jurídicas aplicables. 


\begin{tabular}{|c|c|}
\hline \multirow{2}{*}{ 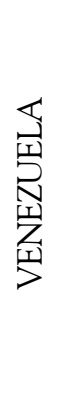 } & $\begin{array}{l}\text { Existen dieciocho fiscalías con competencia ambiental en todo el país, } \\
\text { además de la Dirección General del Medio Ambiente, que dirige y } \\
\text { coordina las actuaciones en materia ambiental con los representantes } \\
\text { del Ministerio Público. }\end{array}$ \\
\hline & $\begin{array}{l}\text { En } 2002 \text { se reformó la Ley Orgánica del Ambiente y se dispuso en el } \\
\text { título XII de su artículo } 156 \text { la instauración de una jurisdicción espe- } \\
\text { cializada penal ambiental; incluso, se contempló la creación de juzga- } \\
\text { dos y tribunales ambientales. Hacia 2009, no existía una jurisdicción } \\
\text { establecida como la dispuesta en dicha ley. }\end{array}$ \\
\hline \multirow{3}{*}{ 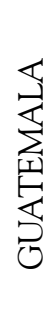 } & $\begin{array}{l}\text { Existe una Unidad de Medio Ambiente que pertenece a la Fiscalía } \\
\text { General de la República y ejerce la persecución penal. }\end{array}$ \\
\hline & $\begin{array}{l}\text { En cuanto a la persecución policial, destaca la existencia de la Policía } \\
\text { de Medio Ambiente, que lleva a cabo la investigación bajo la dirección } \\
\text { funcional de la Fiscalía General. }\end{array}$ \\
\hline & $\begin{array}{l}\text { Existen tres fiscalías ordinarias ambientales: una para la zona occiden- } \\
\text { tal, otra para la zona central y la última para la zona oriental. }\end{array}$ \\
\hline \multirow{4}{*}{ 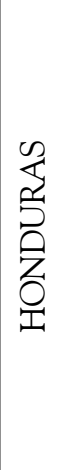 } & $\begin{array}{l}\text { Ejemplarmente, Honduras es el único país que cuenta con un juzga- } \\
\text { do expresamente constituido para la materia ambiental, aunque no de } \\
\text { forma exclusiva. }\end{array}$ \\
\hline & $\begin{array}{l}\text { Son juzgados de primera instancia encargados de delitos contra el am- } \\
\text { biente relacionados a los penales y de narcotráfico. }\end{array}$ \\
\hline & $\begin{array}{l}\text { Existe una Fiscalía de Delitos contra el Ambiente y un Juzgado de Pri- } \\
\text { mera Instancia de Delitos contra el Ambiente. }\end{array}$ \\
\hline & $\begin{array}{l}\text { La Fiscalía de Delitos contra el Ambiente cuenta con un Fiscal de Dis- } \\
\text { trito quien, a su vez, cuenta con fiscales de sección y fiscalías en el } \\
\text { interior del país. }\end{array}$ \\
\hline
\end{tabular}

Por su parte, el desarrollo europeo del derecho penal ambiental se ha confinado estrictamente a la parte sustantiva, pero cuenta, para efectos de la responsabilidad de procesar los tipos penales, con las jurisdicciones penales ordinarias. Así, se puede observar que el espacio europeo no es una expresión de desarrollo en materia procesal penal ambiental. Es, por el contrario, en la experiencia latinoamericana donde se aprecia una interesante tendencia procesal penal ambiental.

\section{PREOCUPACIONES EN MATERIA PROCESAL DE LA JUSTICIA PENAL AMBIENTAL}

En nuestra opinión, los temas recurrentes que se suelen considerar en la perspectiva procesal penal ambiental están relacionados con la especialización de los agentes del sistema y del proceso, lo que, en realidad, nos 
remite a una consideración y reflexión más estructural. Es decir, ¿cuáles son las razones para la existencia de la especialización judicial en asuntos tales como el narcotráfico, el terrorismo, el contrabando y la corrupción? Es evidente que se parte de una lectura político-criminal acerca del impacto de tales conductas, y el conjunto de componentes sociales adscritos a ellas, que conducen a que el sistema se oriente, tendencialmente, a la especialización en la persecución de tales conductas. ¿Por qué la criminalidad ambiental no es considerada un fenómeno relevante y es relegada hacia el sistema punitivo administrativo bajo el manido argumento de la intervención en última ratio, cuando otros escenarios o ámbitos merecen una intervención de prima ratio?

Al respecto, es importante considerar propuestas como la experiencia costarricense en términos de políticas de persecución penal ambiental, ${ }^{19}$ estructuradas en tres grandes temas:

\begin{tabular}{|c|c|c|}
\hline $\begin{array}{l}\text { Políticas de interpretación y } \\
\text { aplicación de los delitos }\end{array}$ & $\begin{array}{c}\text { Políticas } \\
\text { procedimentales }\end{array}$ & $\begin{array}{c}\text { Políticas de investigación } \\
\text { y dirección funcional }\end{array}$ \\
\hline $\begin{array}{l}\text { - Contienen la interpretación ofi- } \\
\text { cial sobre los alcances normati- } \\
\text { vos y los parámetros específicos } \\
\text { de aplicación de cada delito por } \\
\text { parte de los fiscales del Ministe- } \\
\text { rio Público. } \\
\text { - Además, define las prioridades } \\
\text { en la persecución de la delin- } \\
\text { cuencia penal ambiental según } \\
\text { la importancia y escasez del re- } \\
\text { curso a proteger. } \\
\text { - En vista de que en Costa Rica, } \\
\text { en } 2005, \text { existían once leyes que } \\
\text { contienen, aproximadamente, } \\
66 \text { delitos ambientales, se desa- } \\
\text { rrollaron políticas para casi to- } \\
\text { dos ellos y solo algunos de muy } \\
\text { poca aplicación quedaron fuera. } \\
\text { - La mayoría de tales delitos san- } \\
\text { cionan conductas que atentan } \\
\text { directamente contra bienes } \\
\text { ambientales (aunque algunos } \\
\text { no fueron concebidos para ello, } \\
\text { sino para tutelar otros bienes } \\
\text { jurídicos como la salud, la vida, } \\
\text { la propiedad, el dominio pú- } \\
\text { blico, etcétera). No obstante, } \\
\text { estos otros protegen en forma } \\
\text { indirecta el ambiente, lo que ha } \\
\text { permitido adaptarlos a las exi- } \\
\text { gencias de los tiempos moder- } \\
\text { nos y utilizarlos en su defensa. }\end{array}$ & $\begin{array}{l}\text { - Grupo de políticas } \\
\text { que ordena todo lo } \\
\text { relativo a la aplica- } \\
\text { ción de las salidas } \\
\text { alternas en materia } \\
\text { ambiental, que in- } \\
\text { cluye políticas para } \\
\text { la aplicación de la } \\
\text { conciliación y la sus- } \\
\text { pensión del proceso } \\
\text { a prueba, los planes } \\
\text { reparadores y la apli- } \\
\text { cación de otros insti- } \\
\text { tutos como el criterio } \\
\text { de oportunidad, las } \\
\text { medidas cautelares, } \\
\text { etcétera. } \\
\text { - Con este segundo } \\
\text { documento, se tie- } \\
\text { nen por actualizados } \\
\text { los lineamientos de } \\
\text { política criminal que } \\
\text { contenía la circular } \\
2.99 \text {, que queda de- } \\
\text { rogada. }\end{array}$ & $\begin{array}{l}\text { - En este grupo, se diseñó } \\
\text { una serie de protocolos } \\
\text { de actuación que regu- } \\
\text { lan la actividad de los } \\
\text { fiscales en sus relaciones } \\
\text { funcionales con otras } \\
\text { instituciones, para lograr } \\
\text { una mejor comunicación } \\
\text { y coordinación de inves- } \\
\text { tigaciones, denuncias, } \\
\text { operativos, etcétera. } \\
\text { Se desarrollaron aquí los } \\
\text { siguientes instrumentos: } \\
\text { - Protocolo para Decomi- } \\
\text { so, Custodia, Donación } \\
\text { y Comiso de Bienes en } \\
\text { Materia Ambiental. } \\
\text { - Protocolo para el Mane- } \\
\text { jo de las Usurpaciones y } \\
\text { Coordinación Policial. } \\
\text { - Protocolo para el Mane- } \\
\text { jo de Casos de Contami- } \\
\text { nación Hídrica. } \\
\text { - Protocolo para la Valo- } \\
\text { ración del Daño Am- } \\
\text { biental, Manejo de la } \\
\text { Acción Civil con la } \\
\text { Procuraduría General y } \\
\text { Aplicación de Medidas } \\
\text { Cautelares Atípicas. }\end{array}$ \\
\hline
\end{tabular}


Tampoco deja de importar el asunto de la legitimación de los sujetos en un contexto de esclarecimiento entre intereses difusos y colectivos aplicados al Derecho penal ambiental en razón a los intereses concernidos (tutelados) ${ }^{20}$. El Código Procesal Penal (decreto legislativo 957) al referirse a la víctima, en especial al agraviado, señala:

ARTíCULO 94. Definición.- [...] 4. Las asociaciones en los delitos que afectan intereses colectivos o difusos, cuya titularidad lesione a un número indeterminado de personas, o en los delitos incluidos como crímenes internacionales en los Tratados Internacionales aprobados y ratificados por el Perú, podrán ejercer los derechos y facultades atribuidas a las personas directamente ofendidas por el delito, siempre que el objeto social de la misma se vincule directamente con esos intereses y haya sido reconocida e inscrita con anterioridad a la comisión del delito objeto del procedimiento.

Es ostensible en cierta literatura nacional la omisión de abordar consideraciones acerca del tema ambiental (difuso) o similares, como el caso del artículo 94-421.

En realidad, una lectura del CPP en perspectiva ambiental nos conducirá a un redireccionamiento conceptual y pragmático para el juzgamiento de los delitos ambientales, como en el caso de la prueba en el proceso penal ${ }^{22}$, donde, por ejemplo, se presentan dificultades sobre cómo articular los hechos para dar cuenta de la complejidad del daño ambiental en la sede penal. Encontramos la misma preocupación en relación con la intervención y actuación policial ambiental cuando, como se indicó, se carece de una adecuada organización policial sobre la materia que solo funciona bien en determinadas experiencias ${ }^{23}$.

20 MARTínEZ MEJÍA, Wendy. «Intereses difusos y colectivos en el Derecho penal ambiental». En <http:// www. riaej.org/index.php?option=com docman\&task=doc download\&gid=12>.

21 De LA CRUz ESPEJo, Marco. El nuevo proceso penal. Lima: IDEMSA, 2007, p. 908. Rosas YatACO, Jorge. Manual de Derecho procesal penal con aplicación al nuevo proceso penal: decreto legislativo No. 957. Lima: Jurista, 2009, p. 1144.

22 Talavera Elguera, Pablo. La prueba en el nuevo proceso penal: manual del Derecho probatorio y de la valoración de las pruebas en el proceso penal común. Lima: Academia de la Magistratura, GTZ, 2009 , p. 171.

23 SOlER TORMO, Juan Ignacio y Francisco Antón BARBERÁ. Policía y medio ambiente. Granada: Comares, 1996, p. 496. 